\title{
An experimental analysis of performance and exhaust emissions of a CRDI diesel engine operating on mixtures containing mineral and renewable components
}

The manuscript presents a comparative analysis of the performance and emission characteristics of a compression ignition engine equipped with a Common Rail injection system. The engine is fueled with diesel-biodiesel mixtures containing $25 \%$ and $50 \%$ share (by volume) of renewable components. Conventional diesel is used as a reference. Turkey lard and rapeseed oil are used as raw materials and subjected to the single-stage transesterification process to obtain methyl esters. The experiments are performed on a medium-duty, turbocharged, inter-cooled, Common Rail Direct Injection (CRDI) diesel engine. This study concentrates on one engine speed of 1500 rpm, typical for gen-set applications, and mid-load range from $100 \mathrm{Nm}$ to $200 \mathrm{Nm}$. The scope of measurements covers the analysis of exhaust gasses concentration and engine efficiency parameters. In addition, the in-cylinder pressure measurements are performed in order to provide insight into the differences in combustion characteristics between examined fuel mixtures. The study reveals that the addition of the renewable component to fuel mixture positively affects a number of examined performance parameters as well as decreases the concentration of the examined toxic exhaust components, in the majority of cases.

Key words: exhaust emissions, common rail, biodiesel, animal fat biodiesel, combustion analysis

\section{Introduction}

The current stage of technological development still requires combustion engines as the source of propulsion for numerous vehicles and machines. However, due to the vast greenhouse gas (GHG)footprint in combination with diminution of reserves, it is obvious that dependence on energy derived from fossil fuels should be limited. As a result of extensive research, many alternative energy carriers has been developed as a substitution of conventional diesel fuel (DF) [1]. Currently, one of the most promising paths for biofuel production involves the transesterification of raw fatty material with alcohol [2]. Biodiesel, as a product of transesterification, is non-toxic, biodegradable and directly applicable in compression ignition engines (CI) as a standalone fuel, as well as an admixture to DF. Biodiesel can be obtained from a wide range of raw materials including plant oils and animal fats (edible, non-edible or waste quality).

The use of methyl esters causes a number of more or less desirable consequences for engine performance and emissions. Regardless of the origin (plant or animal), the amount (stand-alone fuel or admixture to DF) or type of the engine used (single- or multi-cylinder, equipped with modern or former type injection system) biodiesel is likely to cause reduction of exhaust emission indexes like hydrocarbons and carbon monoxide. On the other hand, the main disadvantages related to biodiesel combustion are the increase in specific fuel consumption and extended emission of oxides of nitrogen [3-5].

In terms of combustion characteristics, biodiesel brings similar effects when compared to conventional DF. However, some significant differences were reported in common rail (CR) engines adopting sequential injection schemes [3, 6].

The aim of the present study is to identify the differences in performance and emission parameters, caused by the use of different fuel composition, in a modern, multicylinder, CI engine operating on a standard (factory) con- troller. The discussion is supported by the results of incylinder pressure measurements.

\section{Materials and methods}

The study concerns biodiesel mixtures produced in the laboratory conditions. Raw fatty materials used for biodiesel production are turkey lard and rapeseed oil. Biofuels are produced by a single-step transesterification reaction of the raw material with methyl alcohol, performed in the presence of an alkaline catalyst (potassium hydroxide), at ambient pressure. The laboratory equipment, as well as reaction parameters, are identical to those described in previous studies $[3,6]$ (alcohol to fatty material molar ratio is6:1, the reaction temperature is $60^{\circ} \mathrm{C} \pm 2^{\circ} \mathrm{C}$, the reaction is carried for 45 minutes). Other activities related to biofuel production concern removal of residual alcohol, glycerol phase, solid impurities, and moisture.

Obtained fatty acid methyl esters (FAMEs) are admixed to DF in volumetric proportions such that the fuel mixture contains $25 \%$ or $50 \%$ of renewable components. Mixtures of the turkey lard methyl esters are labeled as T25and T50, respectively. Corresponding mixtures of the rapeseed oil methyl esters are labeled as R25and R50.

Physicochemical properties of the fuel mixtures and DF are determined according to the procedures specified in PNEN 14214 Standard. The analysis includes the examination of selected parameters: density at $15^{\circ} \mathrm{C}$, viscosity at $40^{\circ} \mathrm{C}$, sulfur content, water content, total contamination and cold filter plugging point (CFPP). The results of the analyzed physicochemical properties are listed in Table 1.

Performance and emission tests are performed on a $2.6 \mathrm{dm}^{3}$, four-cylinder, Common Rail CI engine with Bosch EDC16C39 control unit. The relevant test engine data is presented in Table 2. Remaining elements of the test stand are based on AVL devices (dynometer: Dyno Perform 240; engine speed control system: THA100; fuel balance: 735S; air mass flow meter: SENSYFLOW P; emission 
bench: AMA i60; test stand control and data acquisition system: PUMA Open). The in-cylinder pressure measurement system is provided by KISTLER and coupled with an in-house acquisition and post-processing software, based on the LabVIEW environment. The association of pressure signal with precise crankshaft position is provided by an optical encoder. The in-cylinder pressure signal is recorded with the resolution of 0.1 crank angle degrees (CA). A more comprehensive description of the test stand and procedures for performed experiments is presented in $[7,8]$.

Table 1. Physicochemical properties of the analyzed fuels

\begin{tabular}{|l|c|c|c|c|c|}
\hline Sample & DF & T25 & T50 & R25 & R50 \\
\hline Density at $15^{\circ} \mathrm{C}\left[\mathrm{kg} / \mathrm{m}^{3}\right]$ & 828 & 836 & 849 & 839 & 852 \\
\hline Viscosity at $40^{\circ} \mathrm{C}\left[\mathrm{mm}^{2} / \mathrm{s}\right]$ & 2.80 & 3.08 & 3.37 & 3.15 & 3.52 \\
\hline Sulphur content $[\mathrm{mg} / \mathrm{kg}]$ & 6.1 & 4.41 & 3.37 & 4.74 & 4.09 \\
\hline Water content $[\mathrm{mg} / \mathrm{kg}]$ & 61 & 150 & 244 & 126 & 172 \\
\hline Total contamination $[\mathrm{mg} / \mathrm{kg}]$ & 9 & 13.6 & 17.4 & 11.6 & 15.8 \\
\hline CFPP $\left[{ }^{\circ} \mathrm{C}\right]$ & -12 & -12 & -8 & -12 & -12 \\
\hline
\end{tabular}

Table 2. Technical data of the engine

\begin{tabular}{|l|c|}
\hline Manufacturer & Andoria Mot \\
\hline Engine type & ADCR \\
\hline Number of cylinders / arrangement & 4/in line \\
\hline Fuel injection system & Common Rail, Bosch CR2.0 \\
\hline Displacement volume & $2636 \mathrm{~cm}^{3}$ \\
\hline Rated power / rotational speed & $85 \mathrm{~kW} / 3700 \mathrm{rpm}$ \\
\hline Max. torque / rotational speed & $250 \mathrm{Nm} / 1800-2200 \mathrm{rpm}$ \\
\hline
\end{tabular}

For each test run, the engine rotational speed and load are stabilized with the absolute accuracy of $\pm 5 \mathrm{rpm}$ and $\pm 2 \mathrm{Nm}$, respectively. After the stabilization, steady-state measurements are performed, under predefined engine rotational speed $\mathrm{n}=1500 \mathrm{rpm}$ and the following load conditions: $100 \mathrm{Nm}, 150 \mathrm{Nm}$ and $200 \mathrm{Nm}$. The same measurements are performed for each of the tested samples.

Basic operational parameters of the engine: generated power, fuel, and air consumption and temperatures, as well as in-cylinder pressure and injector coil current, are recorded during the experiments. To expose the differences of efficiency between individual fuel mixtures - brake fuel conversion efficiency (BFCE) was also calculated as a relation between mechanical work performed by the engine and the amount of energy introduced with the fuel.

The concentrations of the hydrocarbons and carbon monoxide are recorded, with the relative accuracy of less than $1 \%$ of the maximum range of the respective analyzer.

\section{Results and discussion}

In the following subsections, the results of BFCE and exhaust gasses concentration, for specific fuel mixtures, are presented as relative values with respect to the diesel reference. The in-cylinder pressure and the injection coil current diagrams in subsection 3.2, present data averaged over 100 consecutive cycles.

\subsection{Fuel conversion efficiency results}

Figure 1 presents the differences in the BFCE for fuel mixtures containing $25 \%$ biocomponents, under the examined operating conditions. Figure 2 show analogous for mixtures with $50 \%$ share of biocomponents.

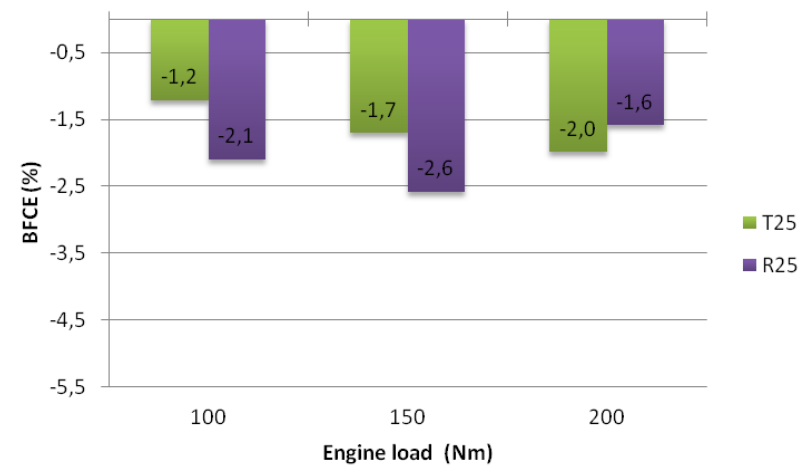

Fig. 1. Changes of BFCE in relation to DF for T25 and R25under different engine load conditions

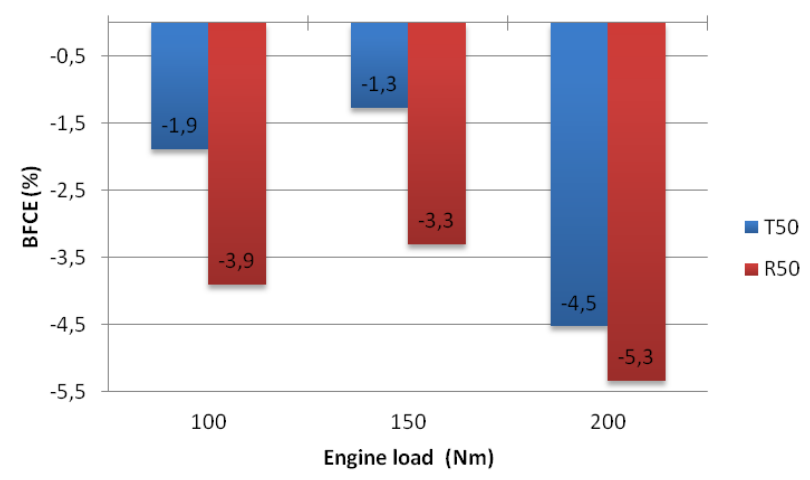

Fig. 2. Changes of BFCE in relation to DF for T50 and R50 under different engine load conditions

Presented results indicate that the biodiesel obtained from turkey lard is characterized by better conversion efficiency than biodiesel obtained from rapeseed oil. The exception is the $200 \mathrm{Nm}$ case (Fig. 1), where the R25 mixture presents better fuel efficiency than T25. Note, however, that the difference between both biofuels does not exceed 0.4 percentage point which is below the level of significance at this specific operating point.

The relation between biodiesel content and fuel efficiency is additionally noted. Mixtures containing higher biodiesel content have been characterized by bigger differences in fuel efficiency in relation to DF, especially under high load conditions (Fig. 2).

\subsection{In-cylinder pressure results}

Figure 3 to Figure 5 present recorded in-cylinder pressure and injection coil current for different loads and fuel mixtures.

The injection actuation signal indicates that for all operating conditions and fuel mixtures, the injected fuel value is divided into two doses - the pilot and the main dose. For both biofuel mixtures, the pilot injection for engine operating conditions of $150 \mathrm{Nm}$ and $200 \mathrm{Nm}$ is significantly advanced from the DF reference (Fig. 4 and Fig. 5). This phenomenon is observed regardless of the biodiesel content in the fuel mixture. Under the engine load of $150 \mathrm{Nm}$ and $200 \mathrm{Nm}$, the injection of the main fuel dose for examined biodiesels is also performed at an earlier stage of the cycle than for DF. This effect is particularly manifesting for mixtures containing biofuel obtained from turkey lard. 

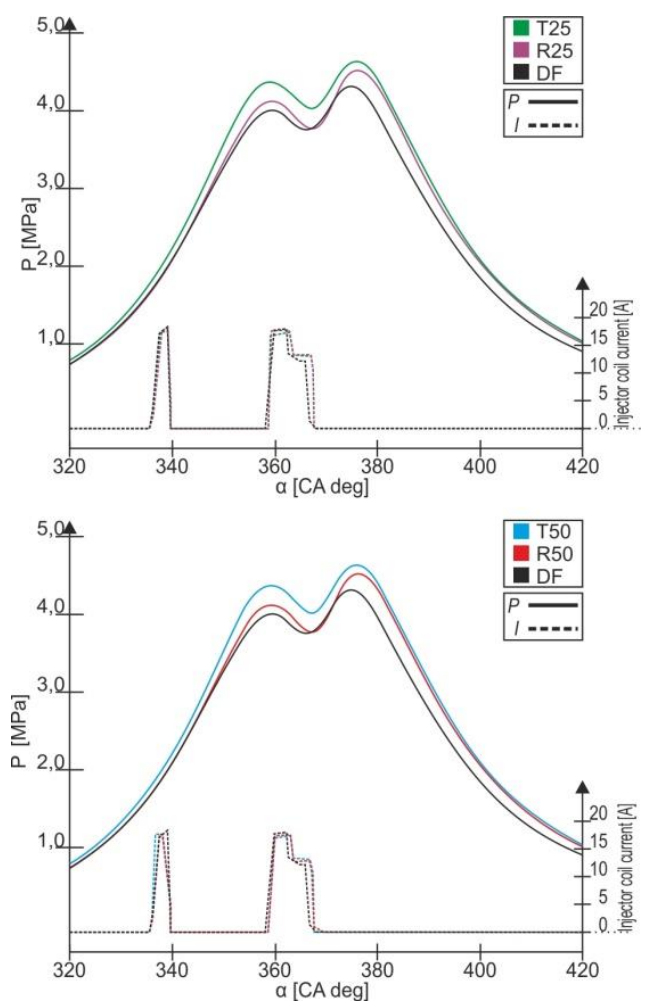

Fig. 3. In-cylinder pressure and injection current versus CA for $100 \mathrm{Nm}$ load
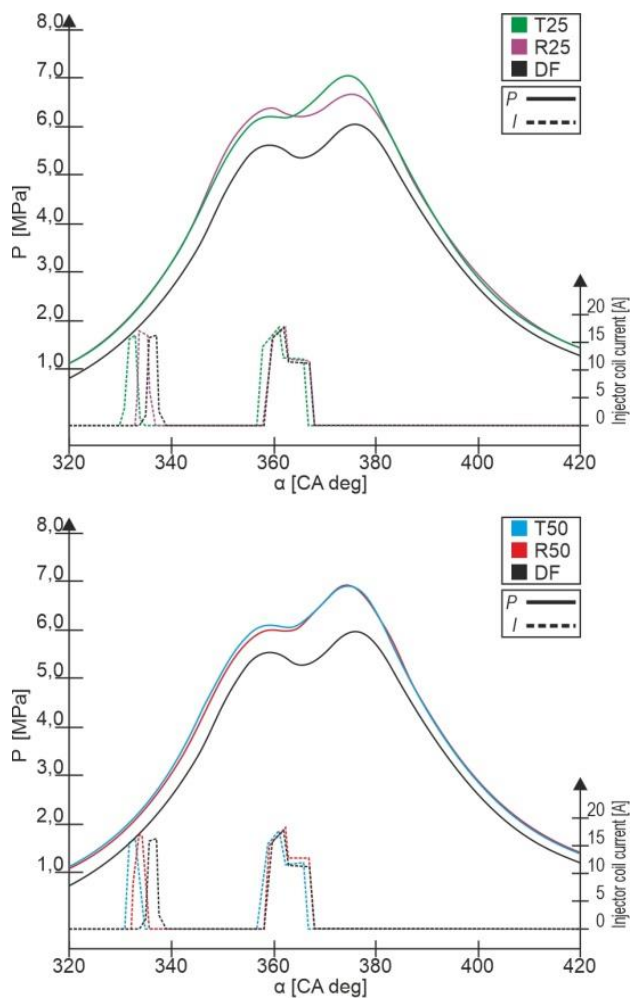

Fig. 4. In-cylinder pressure and injection current versus CA for $150 \mathrm{Nm}$ load

The differences in injection timing for different fuel compositions are introduced by the EDC as a response to differences in fuel properties (physicochemical presented in Table 1, as well as those influencing combustion process resulting from differences in the molecular structure of the mineral and renewable fuel components). Since the EDC controller is optimized for the conventional DF operation, it is difficult to indisputably evaluate the correctness of its operation. However, the differences in injection timing for individual fuel mixtures are reflected in in-cylinder pressure plots.
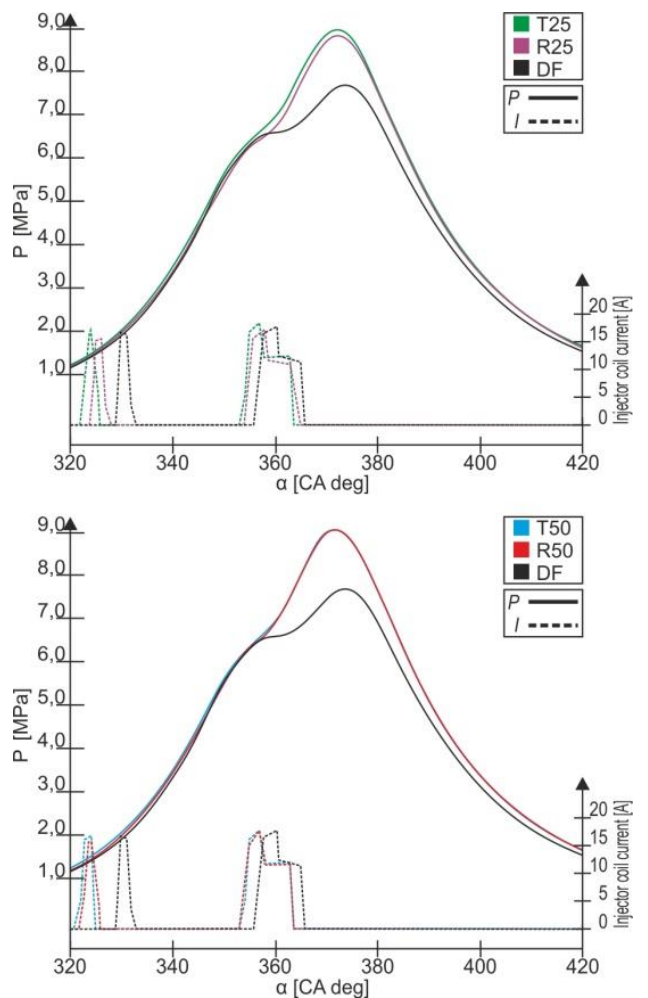

Fig. 5. In-cylinder pressure and injection current versus CA for $200 \mathrm{Nm}$ load

For experiments conducted under $100 \mathrm{Nm}$ load conditions (Fig. 3), mixtures T25 and T50 generate the highest pressure values in the entire analyzed range of the operating cycle. Consequently, the maximum pressure values for fuel mixtures containing both types of admixed biocomponent share significantly higher compared to those recorded during DF operation. This phenomenon is more visible during the experiments performed under the highest examined load (Fig. 5), where T50 and R50 present almost identical values during the whole analyzed part of the cycle (significantly higher form DF). The in-cylinder pressure traces for other fuel mixtures are the reflection of injection timing and highlight the similarities in the combustion behavior of respective biodiesels, despite different feedstock used for their production.

The $150 \mathrm{Nm}$ case (Fig. 4) shows significant differences in the pressure signal between DF and biodiesels. The differences in the in-cylinder pressure occur during the whole analyzed part of the operating cycle. Globally lower pressure values recorded for $\mathrm{DF}$, compared to biodiesels are a result of differences in the amount of air introduced into the combustion chamber. Therefore an increased degree of supercharging can be associated with the use of renewable fuel components at some engine operating points. This is most probably controlled by the EDC (by means of variable 
geometry turbocharger) since increased fuel dosing is applied due to the de-rated heating value of the biofuels. The EDC attempts to maintain the lambda at a value designated by the engine map, thus applying higher boost pressures corresponding to elevated fueling.

As a general remark, the higher indicated pressures in the expansion part of the cycle, observed for both biofuels, suggest that higher indicated work is generated in order to sustain the same break engine load. This indicates consistently higher friction for FAMEs, most probably caused by increased parasitic losses in fuel injection equipment. Those are related to increased fuel viscosity and lower heating value (Table 1). The increased friction would explain the lowest BFCE for rapeseed oil-based biodiesel sample which ultimately score worst, in both fuel parameters (viscosity and LHV), compared to the T25 and T50 samples (see Fig. 1 and Fig. 2). The above thesis is to be checked in a dedicated experimental endeavor,

\subsection{Exhaust gasses concentration results}

Due to the significant discrepancies in the amount of the air introduced into the combustion chamber, during DF and biodiesel operation (Fig. 4), the $150 \mathrm{Nm}$ case has not been discussed in the terms of the exhaust gasses concentration. The postulates based on such differences in engine operating conditions between the individual fuels could lead to misleading conclusions.

Figure 6 and Figure 7 present hydrocarbons concentration, in relation to DF for, specific fuel mixtures. Figure 8 and Figure 9 present the corresponding carbon monoxide emission results.

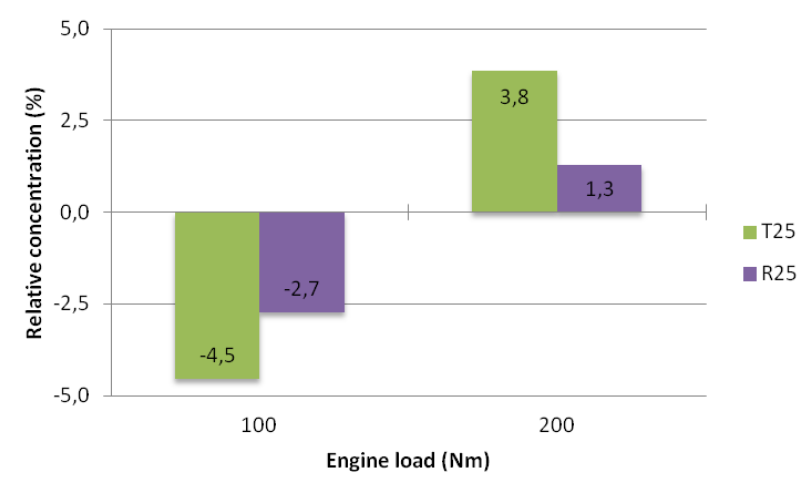

Fig. 6. Hydrocarbons concentration in relation to DF for T25 and R25

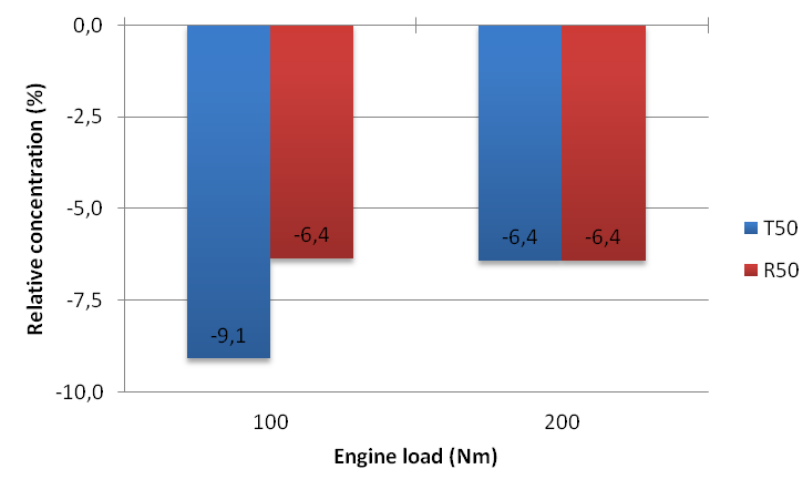

Fig. 7. Hydrocarbons concentration in relation to DF for T50 and R50

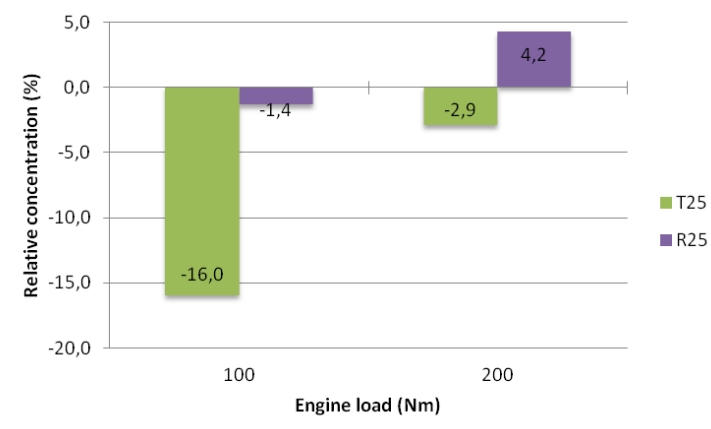

Fig. 8. Carbon monoxide concentration in relation to DF for T25 and R25

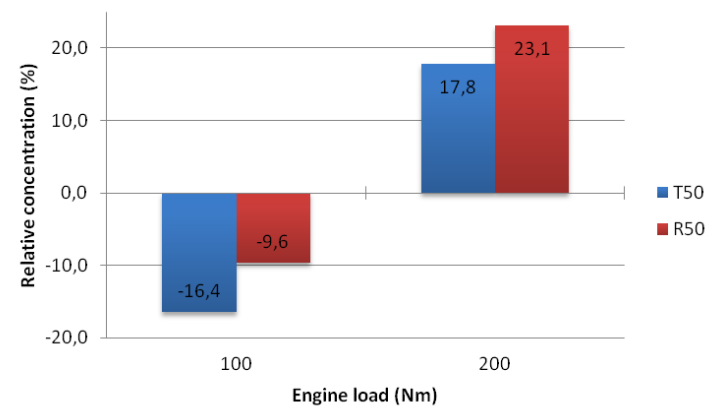

Fig. 9. Carbon monoxide concentration in relation to DF for T50 and R50

For the experiments conducted under $100 \mathrm{Nm}$, the concentrations of hydrocarbons and carbon monoxide are lower compared to DF, regardless of the origin or the quantity of the admixed biocomponent. Significantly better results are obtained for fuel mixtures containing animal origin biocomponents. Since biofuel mixtures containing animalbased FAMEs presented significantly better efficiency results (Fig. 1 and Fig. 2) than plant origin ones, such results are expected. Furthermore, bigger differences are obtained for fuel mixtures containing higher amounts of admixed biocomponents.

During the experiments carried out under $200 \mathrm{Nm}$ load, an increase of carbon monoxide concentration is noted (Fig. 8 and Fig. 9), with the exception for the T25 mixture, for which this emission index decreases slightly. However, in this operating point, the T25 notes a significantly higher concentration of unburned hydrocarbons than the R25 sample (Fig. 6). The reduction of hydrocarbons, along with the increase of carbon monoxide for T50 and R50 (Fig. 7 and Fig. 9) can be explained by significantly earlier injection (thus longer combustion duration) of biodiesel mixtures, compared to DF reference (Fig. 5).

\section{Conclusions}

In the present paper, the engine applicability of turkey lard methyl esters and rapeseed oil methyl esters mixtures are evaluated and compared with diesel fuel. During the course of the study, it is shown that a higher amount of admixed biocomponent reduces fuel efficiency. The biofuels obtained from animal origin raw material generally result in lower deterioration than plant origin components.

The respond of the electronic diesel control unit of the tested engine to biocomponent admixture is manifested in the acceleration of injection timing corresponding to the 
biocomponent share. The use of biodiesel mixtures results in elevated maximum in-cylinder pressure values. In addition, an increased degree of supercharging can be associated with the use of renewable fuel components at some engine operating points.

In terms of exhaust gasses concentration, it is concluded that the increasing share of biocomponents in the fuel mixture causes greater differences in relation to diesel fuel. The use of biodiesel mixtures with $50 \%$ of admixed biocomponents results in a significant reduction of hydrocarbons and carbon monoxide concentrations, especially at the lowest examined engine load conditions. Therefore the $200 \mathrm{Nm}$ load cases generate a lower concentration of hydrocarbons together with increased concentration of carbon monoxide in relation to diesel fuel, consistently for both examined renewable components.

Of all the analyzed fuels containing renewable components, mixtures with animal origin FAMEs, present the most favorable results in terms of efficiency and exhausts concentration.

\section{Nomenclature}

BFCE brake fuel conversion efficiency

CA crank angle

CFPP cold filter plugging point

CI compression ignition

CRDI common rail direct injection

DF diesel fuel

EDC electronic diesel control unit

FAME fatty acid methyl esters

TDC top dead center
R25 fuel mixture containing $25 \%$ of rapeseed oil methyl ester and $75 \%$ of diesel fuel (by volume)

R50 fuel mixture containing 50\% of rapeseed oil methyl ester and $50 \%$ of diesel fuel (by volume)

T25 fuel mixture containing $25 \%$ of turkey lard methyl ester and $75 \%$ of diesel fuel (by volume)

R50 fuel mixture containing 50\% of turkey lard methyl ester and $50 \%$ of diesel fuel (by volume)

\section{Bibliography}

[1] ARANSIOLA, E.F., OJUMU, T.V., OYEKOLA, O.O. et al. A review of current technology for biodiesel production: state of the art. Biomass and Bioenergy. 2014, 61. DOI: 10.1016/j.biombioe.2013.11.014

[2] ABBASZAADEH, A., GHOBADIAN, B., OMIDKHAH, M.R., NAJAFI, G. Current biodiesel production technologies: a comparative review. Energy Conversion and Management. 2012, 63. DOI: 10.1016/j.enconman.2012.02.027

[3] DUDA, K., WIERZBICKI, S., ŚMIEJA, M., MIKULSKI, M. Comparison of performance and emissions of a CRDI diesel engine fuelled with biodiesel of different origin. Fuel. 2018, 212. DOI. 10.1016/j.fuel.2017.09.112

[4] MOFIJUR, M., ATABANI, A.E., MASJUKI, H.H. et al. A study on the effects of promising edible and non-edible biodiesel feedstocks on engine performance and emissions production: a comparative evaluation. Renewable and Sustainable Energy Reviews. 2013, 23. DOI. 10.1016/j.rser. 2013.03.009

Kamil Duda, DSc., DEng. - Faculty of Technical Sciences, University of Warmia and Mazury.

e-mail: kamil.duda@uwm.edu.pl
[5] GRABOSKI, M.S., MCCORMICK, R.L. Combustion of fat and vegetable oil derived fuels in diesel engine. Progress in Energy Combustion Science. 1998, 24(2). DOI: 10.1016/ S0360-1285(97)00034-8

[6] DUDA, K., PIĘTAK, A. Physicochemical properties of fuel compositions obtained from diesel fuel and different kinds of fatty raw material. Journal of KONES Powertrain and Transport. 2018, 25(3). DOI: 10.5604/01.3001.0012.4324

[7] DUDA, K., ŚMIEJA, M., MIKULSKI, M., HUNICZ, J. Influence of biodiesel origin on the exhaust gasses concentration in compression ignition engine. Journal of KONES Powertrain and Transport. 2018, 25(3). DOI. 10.5604/ 01.3001.0012.4325

[8] MIKULSKI, M., DUDA, K., WIERZBICKI, S. Performance and emissions of a CRDI diesel engine fuelled with swine lard methyl esters diesel mixture. Fuel. 2016, 164. DOI 10.1016/j.fuel.2015.09.083

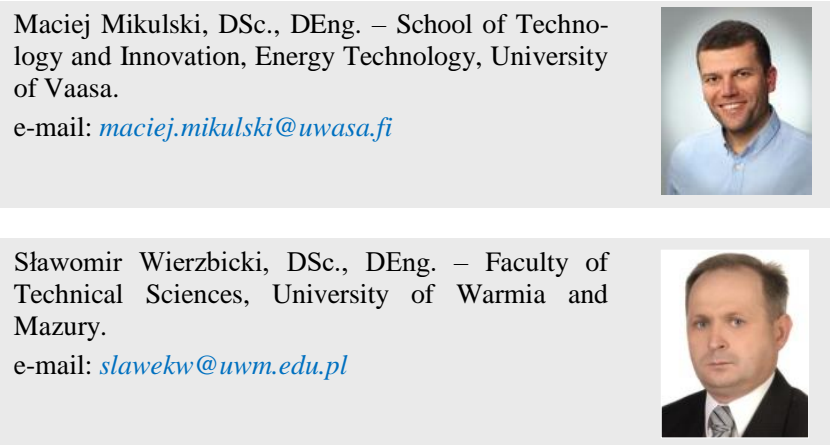
of Vaasa.

Sławomir Wierzbicki, DSc., DEng. - Faculty of Technical Sciences, University of Warmia and Mazury.

e-mail: slawekw@uwm.edu.pl

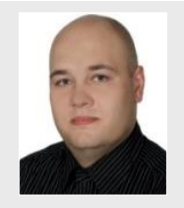
(2) 